\title{
Connexin43 Expression Increases in the Epithelium and Stroma along the Colonic Neoplastic Progression Pathway: Implications for Its Oncogenic Role
}

\author{
Yusheng Han,, ${ }^{1}$ Paul J. Zhang, ${ }^{2}$ Terina Chen, ${ }^{2}$ Sabrina W. Yum, ${ }^{3}$ \\ Teresa Pasha, ${ }^{2}$ and Emma E. Furth ${ }^{2}$ \\ ${ }^{1}$ Department of Pathology and Laboratory Medicine, Pennsylvania Hospital, Philadelphia, PA 19107, USA \\ ${ }^{2}$ Department of Pathology and Laboratory Medicine, Hospital of the University of Pennsylvania, Philadelphia, PA 19104-4280, USA \\ ${ }^{3}$ Division of Neurology, Department of Pediatrics, Children Hospital of Philadelphia, Philadelphia, PA 19104, USA
}

Correspondence should be addressed to Emma E. Furth, eef@mail.med.upenn.edu

Received 22 February 2011; Revised 28 April 2011; Accepted 5 May 2011

Academic Editor: Gianfranco D. Alpini

Copyright ( 2011 Yusheng Han et al. This is an open access article distributed under the Creative Commons Attribution License, which permits unrestricted use, distribution, and reproduction in any medium, provided the original work is properly cited.

Connexins (Cxs) are critical for normal tissue development, differentiation, and cell proliferation. Normal expression and function of Cxs are considered to play a role in tumor suppression, but abnormal localization and abnormally increased expression of Cxs have been found in a variety of carcinomas. Of the Cx family, Cx43 is a most prevalent member and has been known as a downstream target of $\beta$-catenin, a key component of Wnt signaling pathway. We evaluated the expression of Cx43 in the colonic neoplasia progression sequence with additional attention to the stromal component. Resections of 50 colonic adenocarcinomas were stained immunohistochemically for $\mathrm{Cx} 43$ on paraffin embedded sections. Cx43 cytoplasmic expression increased progressively in the colonic adenocarcinoma sequence in both the epithelial [normal $(4 \pm 1)$, adenomatous (20 \pm 2$)$, cancerous $(124 \pm 10)(P<0.01)$ ], and stromal [normal $(19 \pm 1)$, cancerous $(45 \pm 4)(P<0.01)$ ] components. In the epithelial component, Cx43 was expressed lower in stage I adenocarcinomas $(69 \pm 12)$ compared to stage III/IV $(158 \pm 10, P<0.01)$. Additionally, Cx43 was relatively increased in the adenocarcinoma at the invasive tumor front in all stages. Cx43 may play a critical role in the pathogenesis of colon cancer via gap junction or other gap junction independent mechanisms such as the Wnt/ $\beta$-catenin pathway.

\section{Introduction}

Gap junctions are specific cell-to-cell channels formed by two hemichannels each of which is composed of six transmembrane proteins, called connexin $(\mathrm{Cx})$. Gap junctions permit direct exchange of small molecules and subsequently biologic signaling between cells which are critical for tissue development, cellular differentiation, apoptosis, and cell proliferation $[1,2]$. Of the Cx family, Connexin26 (Cx26), 32 (Cx32), and $43(\mathrm{Cx} 43)$ are the most widely studied. While Cxs were initially thought to serve as putative tumor suppressors via normal functioning gap junctions [3-6], more recent studies have found aberrant increased expression of Cxs in a variety of carcinomas and sarcomas [7-9]. In addition, Cxs have also been observed to have transcriptional function independent of their gap junction function $(36,37)$. Because cell contactmediated signaling is important in carcinogenesis by regulating invasion and metastasis [10-12], we hypothesize that Cxs may also serve a role in these processes through gap junction dependent or independent mechanisms. Additionally, because epithelial stromal interactions and signaling are also critical for normal cell biology and cancer cell migration, we hypothesized that the expression of Cxs may be altered in the mesenchymal tissue in neoplastic progression.

Colon cancer is one of the most common cancers in the Western countries and serves as an ideal model system to study neoplastic progression. Specifically, resection specimens usually contain normal colon, the adenomatous precursor lesion, variably invasive cancer, and, depending on stage, metastatic disease. $\mathrm{Cx} 43$, an important member of 
the Cx family, has been shown to be present in the normal human epithelium of the colon $[13,14]$. However, the role of $\mathrm{Cx} 43$ in the physiology of the colon is currently poorly understood. Aberrant Cx43 expression has been found in several types of tumor, including liver, prostate, breast, and lung [12, 15-21]. Importantly, GJA1/Cx43 has been reported to be frequently mutated in tumors of the colon, suggesting that inactivation of $\mathrm{Cx} 43$ can be involved in colorectal carcinogenesis [14]. However, the role of Cx43 in carcinogenesis remains to be elucidated.

Adenomatous polyposis coli (APC) plays important roles in a wide range of cellular functions such as proliferation, migration, differentiation, and apoptosis in colonocytes [2225]. APC is important in Wnt signalling, where it participates together with axin and glycogen synthase kinase 3b (GSK3b) to target the adhesion molecule and transcription factor $\beta$ catenin for degradation. APC mutations have been found in $40-80 \%$ of sporadic colon cancer and in almost all cases of familial adenomatous polyposis [26-28]. The truncated APC gene product causes dysregulation of $\beta$-catenin. When van der Heyden et al. [29] investigated the effects of Wnt1 overexpression on gap junctional communication in PC12 cells, they reported that Wnt1 expressing clones displayed an increased electrical and chemical coupling. This coincided with an increased expression of $\mathrm{Cx} 43 \mathrm{mRNA}$. Also, induction of Wnt1 expression in a mammary epithelial cell line leads to an increase in gap junctional communication and $\mathrm{Cx} 43$ protein expression. In the absence of functional APC, $\beta$-catenin accumulates in the nucleus where it can turn on transcription of several genes, including the gap junction protein $\mathrm{Cx} 43$, COX-2, cyclin-D1, and PPAR $\delta$ [29-33]. Therefore, Cx43 could be a potential biomarker for colorectal carcinoma.

To the best of our knowledge, the importance of connexin43 in colorectal carcinogenesis has not been well investigated. Little is known about the expression of $\mathrm{Cx} 43$ in colorectal carcinoma; especially in clinically and pathologically well-characterized cases, the goal of our study was to evaluate the expression of $\mathrm{Cx} 43$ in a series of well characterized colorectal adenocarcinomas. Specifically, we studied (1) the expression and localization of Cx43 in colon cancer progression sequence with attention to both epithelial and stromal compartments and (2) correlation of $\mathrm{Cx} 43$ expression in colon cancer with its pathologic stage and histologic grade.

\section{Materials and Methods}

This retrospective study was performed in 50 cases of primary resections of colonic adenocarcinoma between the years 2000 to 2005 from the Hospital of the University of Pennsylvania. It was approved by the Institutional Review Boards (IRB). Cases with macroscopic or microscopic residue of tumor cells at the surgical margins and those with preoperative chemo- or irradiation therapy were excluded. All cases were histopathologically diagnosed according to the American Joint Committee on Cancer (AJCC) classification and TNM staging. Lymph node metastases were checked by histopathological examination in all cases. Distant metastases were diagnosed by histopathological examination. A representative block was selected in each case for the study. Normal colonic mucosa was present in the selected block in 37 cases and adenoma in 14 cases.

2.1. Immunohistochemistry. Tissue specimens were fixed in $10 \%$ formalin and embedded in paraffin in all cases. Sections $(5 \mu \mathrm{m})$ were deparaffinized with Xylene 3 times for 3-5 minutes each. Antigen retrieval was performed in $10 \mathrm{mmoL} / \mathrm{L}$ of sodium citrate ( $\mathrm{pH} 7.6)$ in a microwave for 4 minutes twice at $70 \%$ power level. Endogenous peroxidase was inactivated by incubation in 5\% hydrogen peroxide for 5 minutes. Nonspecific binding sites were blocked by incubating with $2 \%$ normal horse serum for 20 minutes. Connexin 43 immunohistochemical stains were performed with a polyclonal goat connexin 43 antibody (clone CXN-6, Santa Cruz Biotechnology) with $1: 200$ dilution and incubation at room temperature for 60 minutes. Immunoreactivity was visualized by using EnVision+ system-HRP labeled polymer on a DAKO autostainer (DAKO, Carpinteria, CA).

Double Cx43 and Beta-Catenin Staining. Cx43 stain was performed as above said. Afterwards the beta-catenin stain was performed manually. After boiled in $1 \times$ citrate buffer for 20 minutes, sections were incubated with mouse antibeta-catenin antibody (monoclonal, BD Bioscience cat no. $610154)$ at $1: 250$ dilution for 30 minutes at room temperature followed by alkaline phosphatase-conjugated goat antimouse antibody (DAKO, Carpinteria, CA) at 1:75 dilution for 30 minutes and then exposed to Perma Red (Dako, Carpinteria, CA) for 5 minutes at RT and counterstained with hematoxylin.

\subsection{Evaluation of $C x 43$ Immunostaining. Cx43 immunos-} taining was evaluated by three authors independently, blinded to patient outcome and all clinicopathologic findings. The immunohistochemical staining was analyzed and classified into four groups based on the staining intensity $(0$, absent; $1+$, weak; $2+$, intermediate; $3+$, strong staining). The percentage (\%) and staining intensity (0-3) of epithelial and stromal cells in normal, adenomatous, and cancerous areas were determined. The total staining score was calculated by the sum of staining intensity multiplied by its percentage yielding a possible score of $0-300$. In the case of heterogeneous staining within the same sample, we determined the percentage of different staining intensities individually in each area and calculated the total sum.

2.3. Statistical Analysis. Statistical analysis was done using the Stata software (StataCorp, College Station, TX). The association of staining intensity with clinicopathologic patterns was assessed with unpaired Student $t$-test, when appropriate. All data were expressed as the mean \pm SR. $P$ values of $<0.05$ were accepted as statistically significant.

\section{Results}

3.1. Clinicopathological Characteristics of Patients with Colon Cancer. The average age of the patients was 61 years (range, 
TABLE 1: Clinicopathological characteristics of patients with colon cancer.

\begin{tabular}{lccc}
\hline Parameters & Stage I $(N=19)$ & Stag III/IV $(N=31)$ & $P$ \\
\hline Median age & $60.0 \pm 14.0$ & $61.5 \pm 10.5$ & $>0.05$ \\
Male : female ratio & $8: 11$ & $18: 13$ & \\
Histologic grade & & & \\
WD & 2 & 21 & \\
MD & 15 & 10 & $>0.05$ \\
PD & 2 & 0.05 \\
\hline
\end{tabular}

WD: Well differentiated, MD: Moderately differentiated, PD: Poorly differentiate.

$1+$

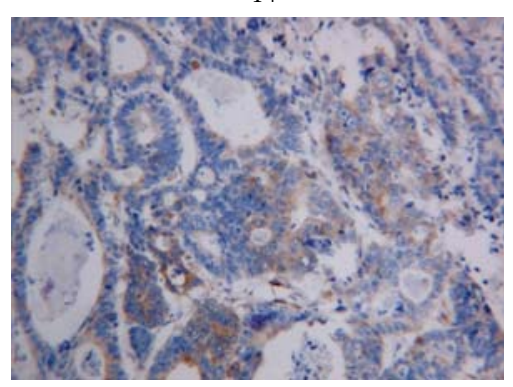

(a)

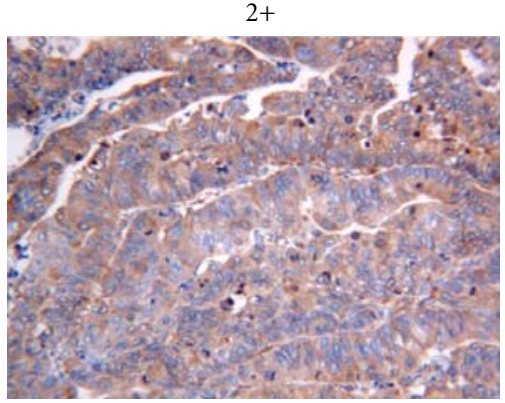

(b)

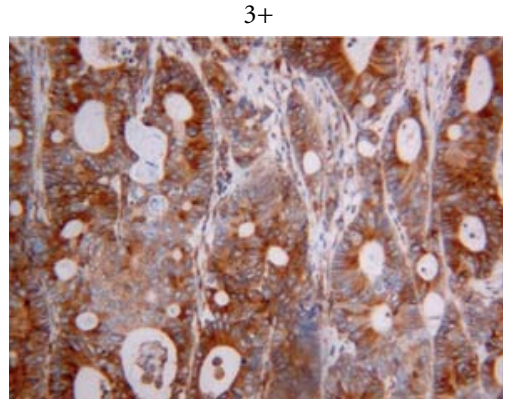

(c)

FIGURE 1: The expression of $\mathrm{Cx} 43$ in colonic adenocarcinoma was evaluated according to the intensity of the staining as follows: 1 , very weak expression (1+); 2, moderate expression (2+); 3, strong expression $(3+)$ (Original magnification $\times 200)$.

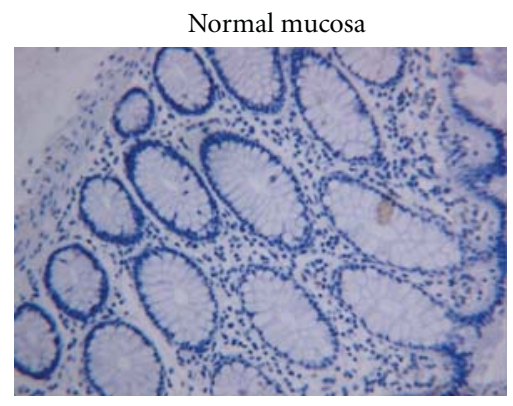

(a)

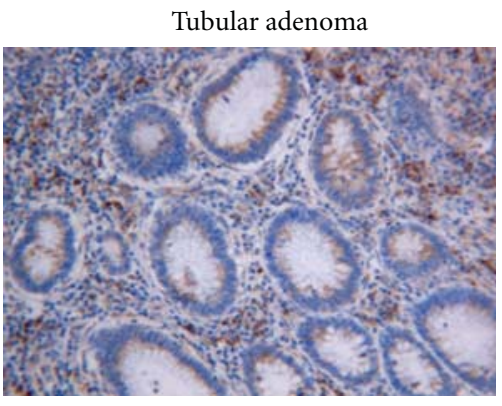

(b)

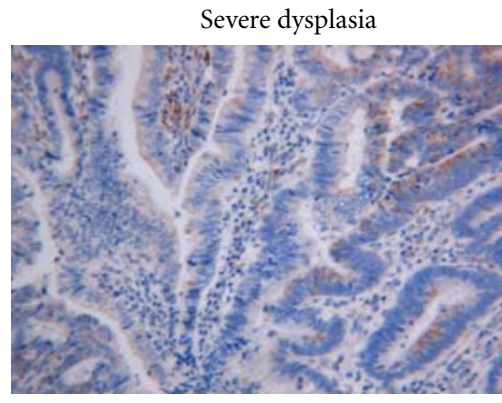

(c)

FIgure 2: The expression of $\mathrm{Cx} 43$ in normal colonic mucosa, tubular adenoma, and severe dysplasia (Original magnification $\times 200$ ). There is an increase in cytoplasmic Cx43 expression from normal epithelium (Cx43 score $4 \pm 1$ ) to tubular adenoma/severe dysplasia (Cx43 score $20 \pm 2)$.

35-82; SD, 14.28 years). Of 50 patients, 19 (38\%) were diagnosed as AJCC TNM stage I, 22 (44\%) were diagnosed as stage III, and 9 (18\%) were diagnosed as stage IV. Histological grades of the tumor are low in 2 (4\%), moderate in 36 $(72 \%)$, and high in $12(24 \%)$ cases. There is no significant difference in age and sex between stage I and stage III/IV (Table 1). Although more cases with poorly differentiated adenocarcinoma in stage III/IV are seen, there is no histologic grade difference between stage I and stage III/IV (Table 1).

3.2. Expression of Cx43 in the Neoplastic Epithelium (Colon Cancer Progression Pathway). Figure 1 depicts the different $\mathrm{Cx} 43$ staining intensity in colorectal adenocarcinoma.
Although Cx43 protein was reported to express in normal colonic mucosa [14], we only rarely observed punctuate intercellular staining of $\mathrm{Cx} 43$ in normal colonic mucosa. In contrast, we found a progressive increase in cytoplasmic Cx43 expression from normal epithelium to tubular adeno$\mathrm{ma} /$ severe dysplasia (Figure 2) and to carcinoma (Figure 3 ). Cx43 score according to each histologic category was recorded as $4 \pm 1$ in normal $(n=37), 20 \pm 2$ in adenoma $(n=14)$, and $124 \pm 10$ in cancer $(n=50)(P<0.01)$. Variable Cx43 expression was detected in colon cancer tissues in all cases (50/50). Cx43 was expressed predominantly in the cytoplasm in colon cancer and precancer epithelia, although a mixed (cytoplasmic and membranous) staining in stage III/IV colonic carcinoma was seen. Additionally, Cx43 
Stage I

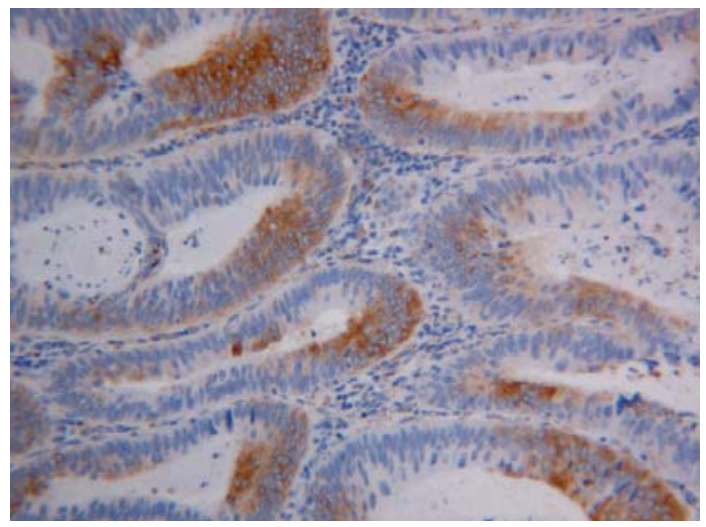

(a)
Stage III/IV

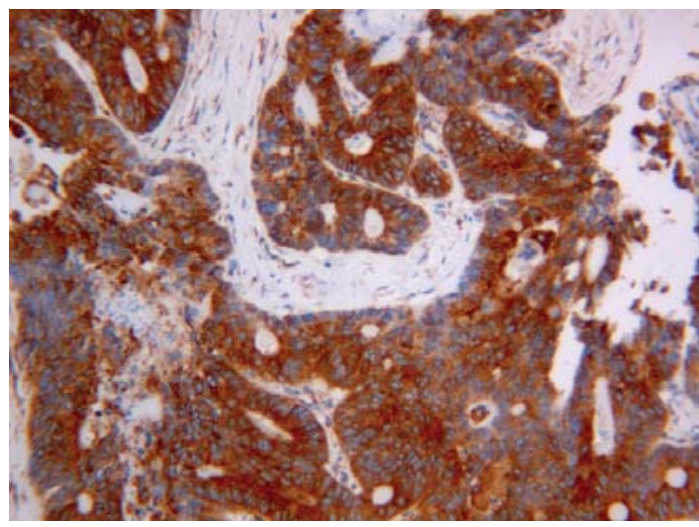

(b)

Figure 3: The difference in Cx43 expression in stage I and stage III/IV colonic adenocarcinoma (original magnification $\times 200$ ). A higher level of Cx43 expression was significantly associated with AJCC stage III/IV adenocarcinomas (Cx43 score 158 \pm 10 ), as compared to AJCC stage I (Cx43 score $69 \pm 12)$.

$1+$

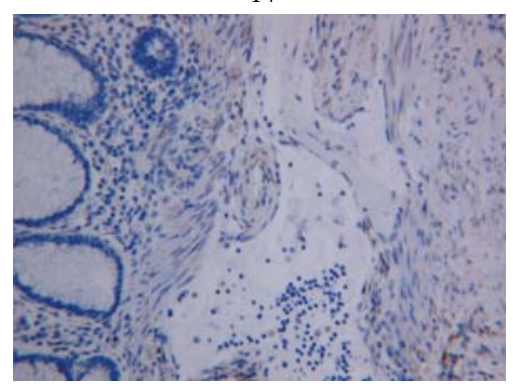

(a)

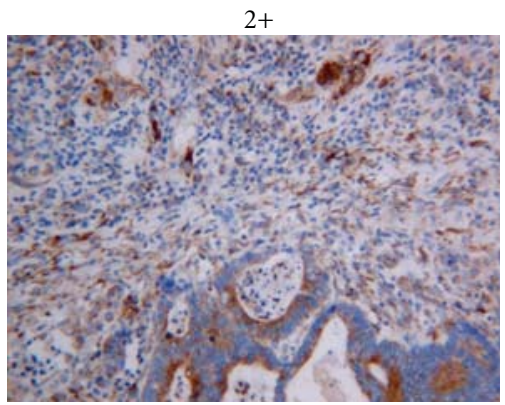

(b)

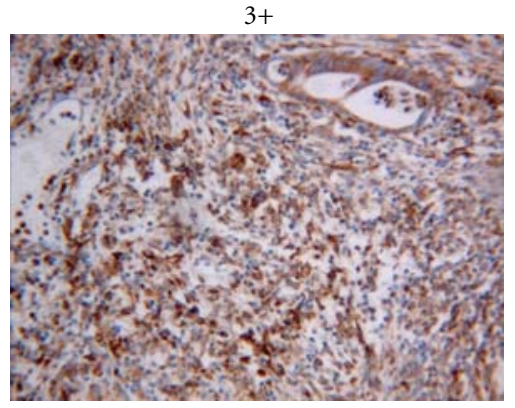

(c)

FIGURE 4: The expression of Cx43 in colonic stroma was evaluated according to the intensity of the staining as follows: 1 , very weak expression $(1+) ; 2$, moderate expression $(2+) ; 3$, strong expression $(3+)$ (original magnification $\times 200$ ).

reactivity was relatively increased in the invasive front of the adenocarcinoma in all cases of different stages (data not shown).

\subsection{Expression of Cx43 in Stromal Component. Cx43 expres-} sion was also localized to connective tissue and muscular tissue in the samples, primarily in the connective tissue in close proximity to epithelial cells (Figure 4 ). Cx43 reactivity was stronger in the stromal components adjacent to cancerous epithelium than benign epithelium: normal ( $\mathrm{Cx} 43$ score $19 \pm 1)$, cancer $(\mathrm{Cx} 43$ score $45 \pm 4)(P<0.01)$ (Figure 6). However, there is no significant stage difference (Stage I: $42 \pm 4$, Stage III/IV: $46 \pm 6)(P>0.05)$.

\subsection{Expression of Cx43 in Colonic Adenocarcinoma in Relation} to Stage and Grade. A higher level of Cx43 expression was significantly associated with AJCC stage III/IV adenocarcinomas $(158 \pm 10),(P<0.01)$ as compared to AJCC stage I $(69 \pm 12)$ (Figure 3$). \mathrm{Cx} 43$ expression did not show any correlation with histologic grade.
3.5. Coexpression of $\mathrm{Cx} 43$ and Beta-Catenin. After evaluation of the initial Cx43 staining, 12 cases, 6 with low Cx43 reactivity and 6 with high Cx43 reactivity, were selected for double staining. Nuclear and sometimes cytoplasmic betacatenin reactivity (red) was observed in neoplastic cells. However, for practical reason, only nuclear reactivity was analyzed against the $\mathrm{Cx} 43$ cytoplasmic reactivity (brown) on double staining. No nuclear beta-catenin reactivity was detected in nonneoplastic colonic epithelium. Coexpression of $\mathrm{Cx} 43$ and beta-catenin was commonly seen but is not exclusive as other tumor cells in the same tumor frequently exhibited only either $\mathrm{Cx} 43$ or beta-catenin. There was no correlation in the level of immunoreactivity between $\mathrm{Cx} 43$ and beta-catenin (data not shown). No nuclear beta-catenin reactivity was detected in any stromal cells regardless of their Cx43 reactivity (Figure 5).

\section{Discussion}

It was suggested that loss of gap junction protein expression, aberrant cytoplasmic localization, and disturbance of gap 


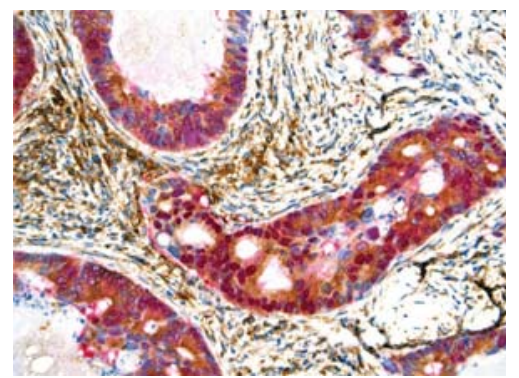

(a)

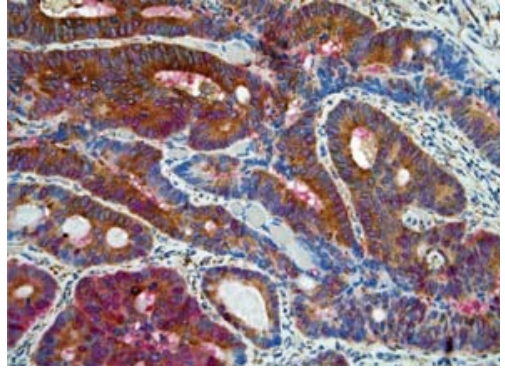

(b)

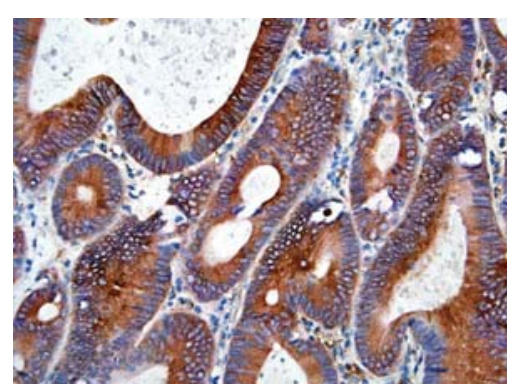

(c)

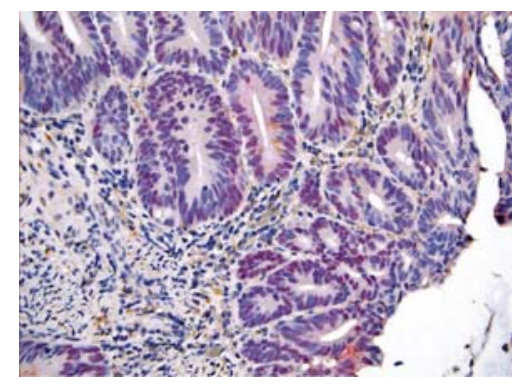

(d)

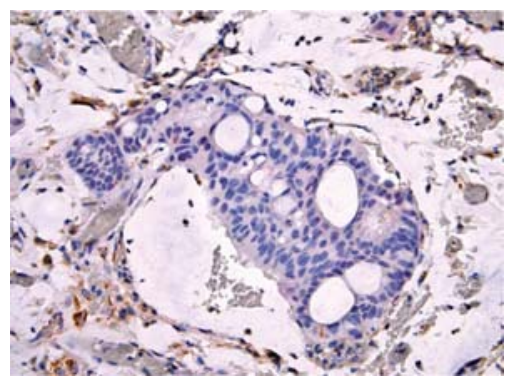

(e)

Figure 5: The relationship between Cx43 expression and nuclear beta-catenin expression in colonic adenocarcinoma (original magnification $\times 200$ ). (a) Coexpression of $\mathrm{Cx} 43$ (brown cytoplasmic staining) and nuclear beta-catenin (red nuclear staining). Note. Peritumoral stromal cells exhibited only $\mathrm{Cx} 43$ but not beta-catenin reactivity. (b) Tumoral tissue exhibited heterogeneous expression of Cx43 and nuclear betacatenin. (c) Tumoral tissue with expression of Cx43 only. (d) Tumoral tissue with expression of beta-catenin only. (e) Tumoral tissue with no expression of $\mathrm{Cx} 43$ or beta-catenin.

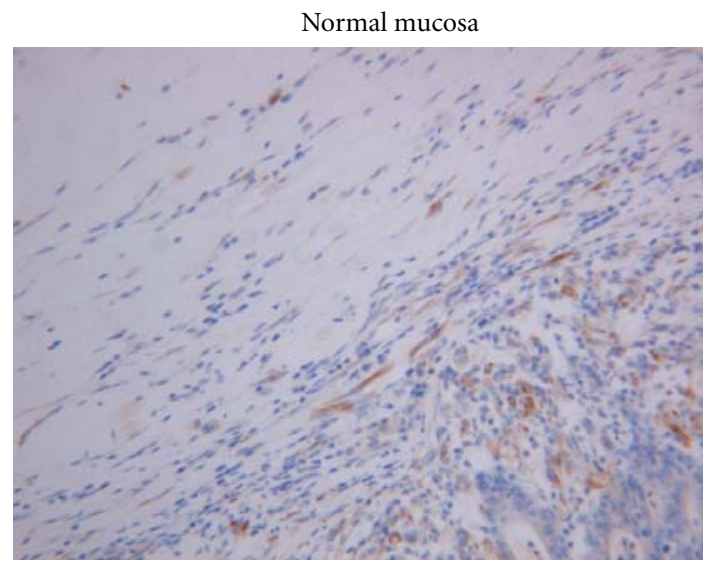

(a)

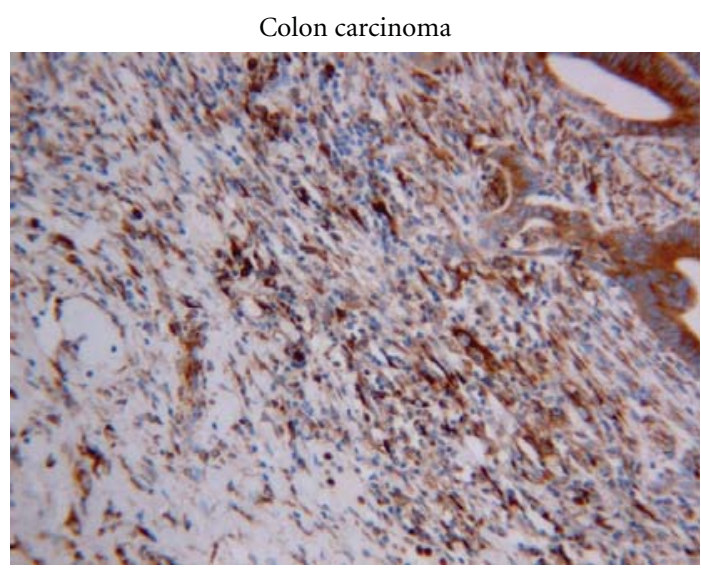

(b)

Figure 6: The difference in $\mathrm{Cx} 43$ expression in the stromal component in normal mucosa and colonic adenocarcinoma (original magnification $\times 200$ ). Cx43 reactivity was stronger in the stromal components adjacent to cancerous epithelium than benign epithelium: normal (Cx43 score $19 \pm 1)$, cancer (Cx43 score $45 \pm 4)$.

junction intercellular communication would be important events in carcinogenesis, invasion, and metastasis [12, 34]. There has been a large body of literature to suggest that gap junctions are implicated in cellular growth control and tissue differentiation, and normal membranous expression of Cxs has tumor suppressive effect that controls tumor progression by regulating cell growth and differentiation. However, the role of Cxs in carcinogenesis and metastasis remains controversial, because it is still unclear whether $\mathrm{Cx}$ expression is required for invasion and metastasizing [35].

In our study, the intercellular/membranous staining was rare and only sporadically seen in normal colonic epithelium, but cytoplasmic expression of $\mathrm{Cx} 43$ was frequently observed in colonic cancer cells. In addition, we found that the level of Cx43 expression was significantly associated with higher AJCC stage III/IV but did not have impact on the histological 
grading. We speculate that cytoplasmic expression of $\mathrm{Cx} 43$ might reflect transcriptional or posttranscriptional defects of this protein during colorectal carcinogenesis, or a product of the mutated gene, a common event in colorectal cancer [14]. If connexins do not assemble to form functional gap junction channels such as in the case of aberrant cytoplasmic accumulation and expression, they might cause alteration in expression of different genes in cooperation with other proteins $[36,37]$, or they may function as adhesion proteins to form adhesive plaques that could severely impair signaling pathways [38]. It has been demonstrated that loss of intercellular communication correlates with high metastatic potential of mammary adenocarcinoma cells [18] and that connexins may be involved in intravasation and extravasation of lung cancerous cells [12]. It has been speculated that connexins may play an important role in the extravasation of cancerous cells into lymphoid tissue by formation of gap junctions between tumor cells and endothelial cells in lymph node vessels [18]. Increased expression of $\mathrm{Cx} 43$ has been reported in lymph node metastases compared to primary tumor to suggest a potential role of $\mathrm{Cx} 43$ in metastatic process $[18,39]$. Dubina et al. [14] reported that the mutational alterations in the carboxylterminal region of $\mathrm{Cx} 43$ are involved in advanced stages of progression of human colon cancer. The carboxyl-terminal tail of Cx43 contains several motifs for phosphorylation by different protein kinases, which is essential for trafficking, gap junction assembly, channel gating, and turnover of Cx43. The frameshift mutations in colon tumors appear to abolish particularly effectively most if not all functional properties of this part of the protein and thus could have a strong impact on cell growth, morphology, and motility that would be critical for cancer progression. However, the fact that $\mathrm{Cx} 43$ mutations have been found only in invasive structures of exophytic colon adenocarcinoma, but neither among their benign precursors adenomatous polyps nor in endophytic carcinomas, suggests that $\mathrm{Cx} 43$ mutational alterations are limited to this specific growth type of human colon neoplasms and are involved at a fairly late stage of their progression [14]. Nevertheless, more and more evidences have merged to suggest that the loss of normal function of connexins during carcinogenesis is not only due to gene mutations, but, more importantly, also due to the multiple steps of possible alteration in connexin expression, including lack of transcription of connexin genes, lack of translation of connexin mRNA, and lack of membrane targeting leading to accumulation of connexin proteins in the cytoplasm. As $\mathrm{Cx} 43$ is a target for $\beta$ catenin/Tcf-mediated transcription [29], accumulated $\beta$ catenin in colon cancer may increase Cx43 expression in colonic mucosal epithelium. This hypothesis was supported by the finding in cardiomyocytes in which $\beta$-catenin was shown to interact directly with $\mathrm{Cx} 43$ and to transactivate Cx43 [40]. Our study of double staining revealed that colorectal adenocarcinomas commonly expressed both betacatenin and $\mathrm{Cx} 43$ in the same or different cells but failed to demonstrate correlation of expression of these two factors in situ. However, these results were not completely unexpected given the fact that beta-catenin immunoreactivity has not been consistently shown to correlate with various pathologic and clinical parameters of colorectal cancer in literatures $[41,42]$. The role of beta-catenin in regulating $\mathrm{Cx}_{4} 43$ in colorectal cancer is likely more complex than expected and needs to be further evaluated. The lack of any nuclear betacatenin reactivity seen in the $\mathrm{Cx} 43$ positive peritumoral stromal cells also suggested other pathways involved in Cx43 expression in colorectal cancer. In any case, our findings of higher $\mathrm{Cx} 43$ expression in neoplastic epithelium and advanced stage of colorectal cancer are consistent with these previous observations on the role of $\mathrm{Cx} 43$ in clinically wellcharacterized cases and suggest an oncogenic role of $\mathrm{Cx} 43$ which might be gap junction dependent or independent.

Cx43 expression was also located to connective tissue and muscular tissue in benign bowel and colon cancer. We observed that $\mathrm{Cx} 43$ was relatively elevated in the connective tissue in close proximity to epithelial cells, and higher Cx43 reactivity was in the stromal components adjacent to cancer than to benign epithelium. It is thought that the role of gap junctions in epithelial-stromal interactions may be important in carcinogenesis. Husøy et al. [30] found an increased expression of $\mathrm{Cx} 43$ in the stroma around intestinal tumors in animal (mice) with the multiple intestinal neoplasia (Min). Furthermore, the increased Cx43 expression in stromal myofibroblasts was colocalized with COX-2, which expression is well known to be increased in both humans and mice adenomas. Myofibroblasts are suggested to secrete signaling molecules that could stimulate invasion of cancer cells, since primary cultures of subepithelial myofibroblasts from human colon promote the migration of epithelial cells [43]. Similar to adenomas in Min mouse intestine, Cx43 has also been reported to be increased in stromal cells of human breast carcinomas. Therefore, it is conceivable that peritumoral stromal Cx43 expression observed in our study might reflect a similar biologic function of $\mathrm{Cx} 43$ in colonic carcinogenesis as observed in the animal and experimental models. The significance of increased peritumoral stromal Cx43 expression in carcinogenesis needs to be further investigated for its role in epithelial-mesenchymal transition/interaction.

In conclusion, in this study, we have found that the level of $\mathrm{Cx} 43$ expression progressively increased along the colonic carcinoma progression sequence and advanced tumor stage in the neoplastic epithelium and the stroma surrounding cancerous epithelium. The findings suggest that connexin43 may play a critical role in the pathogenesis of colon cancer likely via multifactorial mechanisms including, but not limited to, abnormal gap junction formation, transcriptional activity of cytoplasmic Cx43, and abnormal epithelial-stromal interactions. Study is needed to further understand the molecular basis of $\mathrm{Cx} 43$ oncologic effect in colon cancer and how $\mathrm{Cx} 43$ is regulated in colonic carcinoma progression sequence. Immunohistochemical evaluation of Cx43 expression might have prognostic significance as there is a correlation of significantly higher level of $\mathrm{Cx} 43$ expression with more advanced stage colon carcinomas. However, evaluation of Cx43 in larger cohort of cases with clinical outcome data is needed to further assess this potential prognostic role of Cx43 in colorectal cancer. 


\section{References}

[1] L. Kanczuga-Koda, S. Sulkowski, A. Lenczewski et al., "Increased expression of connexins 26 and 43 in lymph node metastases of breast cancer," Journal of Clinical Pathology, vol. 59, no. 4, pp. 429-433, 2006.

[2] V. A. Krutovskikh, C. Piccoli, and H. Yamasaki, "Gap junction intercellular communication propagates cell death in cancerous cells," Oncogene, vol. 21, no. 13, pp. 1989-1999, 2002.

[3] J. E. Trosko and R. J. Ruch, "Cell-cell communication in carcinogenesis," Frontiers in Bioscience, vol. 3, pp. 208-236, 1998.

[4] S. Umhauer, R. J. Ruch, and J. Fanning, "Gap junctional intercellular communication and connexin 43 expression in ovarian carcinoma," American Journal of Obstetrics and Gynecology, vol. 182, no. 5, pp. 999-1000, 2000.

[5] R. J. Ruch, S. Porter, L. D. Koffler, L. D. Dwyer-Nield, and A. M. Malkinson, "Defective gap junctional intercellular communication in lung cancer: loss of an important mediator of tissue homeostasis and phenotypic regulation," Experimental Lung Research, vol. 27, no. 3, pp. 231-243, 2001.

[6] J. Gee, M. Tanaka, and H. B. Grossman, "Connexin 26 is abnormally expressed in bladder cancer," Journal of Urology, vol. 169, no. 3, pp. 1135-1137, 2003.

[7] D. C. Bates, W. C. Sin, Q. Aftab, and C. C. Naus, "Connexin43 enhances glioma invasion by a mechanism involving the carboxy terminus," GLIA, vol. 55, no. 15, pp. 1554-1564, 2007.

[8] S. H. M. Graeber and D. F. Hülser, "Connexin transfection induces invasive properties in HeLa cells," Experimental Cell Research, vol. 243, no. 1, pp. 142-149, 1998.

[9] L. Cronier, S. Crespin, P. O. Strale, N. Defamie, and M. Mesnil, "Gap junctions and cancer: new functions for an old story," Antioxidants \& Redox Signaling, vol. 11, no. 2, pp. 323-338, 2009.

[10] T. Aasen, M. B. Hodgins, M. Edward, and S. V. Graham, "The relationship between connexins, gap junctions, tissue architecture and tumour invasion, as studied in a novel in vitro model of HPV-16-associated cervical cancer progression," Oncogene, vol. 22, no. 39, pp. 7969-7980, 2003.

[11] J. H. C. Lin, T. Takano, M. L. Cotrina et al., "Connexin 43 Enhances the adhesivity and mediates the invasion of malignant glioma cells," Journal of Neuroscience, vol. 22, no. 11, pp. 4302-4311, 2002.

[12] M. E. El-Sabban and B. U. Pauli, "Adhesion-mediated gap junctional communication between lung-metastatatic cancer cells and endothelium," Invasion and Metastasis, vol. 14, no. 16, pp. 164-176, 1994.

[13] L. Nemeth, S. Maddur, and P. Puri, "Immunolocalization of the gap junction protein connexin 43 in the interstitial cells of cajal in the normal and hirschsprung's disease bowel," Journal of Pediatric Surgery, vol. 35, no. 6, pp. 823-828, 2000.

[14] M. V. Dubina, N. A. Iatckii, D. E. Popov, S. V. Vasil'ev, and V. A. Krutovskikh, "Connexin 43, but not connexin 32, is mutated at advanced stages of human sporadic colon cancer," Oncogene, vol. 21, no. 32, pp. 4992-4996, 2002.

[15] I. S. Sheen, K. S. Jeng, P. C. Wang et al., "Are gap junction gene connexins 26, 32 and 43 of prognostic values in hepatocellular carcinoma? A prospective study," World Journal of Gastroenterology, vol. 10, no. 19, pp. 2785-2790, 2004.

[16] D. Zhang, M. Kaneda, K. I. Nakahama, S. Arii, and I. Morita, "Connexin 43 expression promotes malignancy of $\mathrm{HuH7}$ hepatocellular carcinoma cells via the inhibition of cell-cell communication," Cancer Letters, vol. 252, no. 2, pp. 208-215, 2007.
[17] A. Daniel-Wójcik, K. Misztal, I. Bechyne et al., "Cell motility affects the intensity of gap junctional coupling in prostate carcinoma and melanoma cell populations," International Journal of Oncology, vol. 33, no. 2, pp. 309-315, 2008.

[18] L. Kanczuga-Koda, S. Sulkowski, A. Lenczewski et al., "Increased expression of connexins 26 and 43 in lymph node metastases of breast cancer," Journal of Clinical Pathology, vol. 59, no. 4, pp. 429-433, 2006.

[19] M. A. Pollmann, Q. Shao, D. W. Laird, and M. Sandig, "Connexin 43 mediated gap junctional communication enhances breast tumor cell diapedesis in culture," Breast Cancer Research, vol. 7, no. 4, pp. R522-R534, 2005.

[20] M. K. Elzarrad, A. Haroon, K. Willecke, R. Dobrowolski, M. N. Gillespie, and A. B. Al-Mehdi, "Connexin-43 upregulation in micrometastases and tumor vasculature and its role in tumor cell attachment to pulmonary endothelium," BMC Medicine, vol. 6, article 20, 2008.

[21] J. T. Chen, Y. W. Cheng, M. C. Chou et al., "The correlation between aberrant connexin 43 mRNA expression induced by promoter methylation and nodal micrometastasis in nonsmall cell lung cancer," Clinical Cancer Research, vol. 9, no. 11, pp. 4200-4204, 2003.

[22] N. N. Mahmoud, R. T. Bilinski, M. R. Churchill, W. Edelmann, R. Kucherlapati, and M. M. Bertagnolli, "Genotypephenotype correlation in murine Apc mutation: differences in enterocyte migration and response to sulindac," Cancer Research, vol. 59, no. 2, pp. 353-359, 1999.

[23] G. H. Baeg, A. Matsumine, T. Kuroda et al., "The tumour suppressor gene product APC blocks cell cycle progression from G0/G1 to S phase," The EMBO Journal, vol. 14, no. 22, pp. 5618-5625, 1995.

[24] P. J. Morin, B. Vogelstein, and K. W. Kinzler, "Apoptosis and APC in colorectal tumorigenesis," Proceedings of the National Academy of Sciences of the United States of America, vol. 93, no. 15, pp. 7950-7954, 1996.

[25] M. H. Wong, M. L. Hermiston, A. J. Syder, and J. I. Gordon, "Forced expression of the tumor suppressor adenomatosis polyposis coli protein induces disordered cell migration in the intestinal epithelium," Proceedings of the National Academy of Sciences of the United States of America, vol. 93, no. 18, pp. 9588-9593, 1996.

[26] S. Cottrell, D. Bicknell, L. Kaklamanis, and W. F. Bodmer, "Molecular analysis of APC mutations in familial adenomatous polyposis and sporadic colon carcinomas," The Lancet, vol. 340, no. 8820, pp. 626-630, 1992.

[27] A. B. Sparks, P. J. Morin, B. Vogelstein, and K. W. Kinzler, "Mutational analysis of the APC/beta-catenin/Tcf pathway in colorectal cancer," Cancer Research, vol. 58, no. 6, pp. 11301134, 1998.

[28] K. Otori, M. Konishi, K. Sugiyama et al., "Infrequent somatic mutation of the adenomatous polyposis coli gene in aberrant crypt foci of human colon tissue," Cancer, vol. 83, no. 5, pp. 896-900, 1998.

[29] M. A. G. van der Heyden, M. B. Rook, M. M. P. Hermans et al., "Identification of connexin 43 as a functional target for Wnt signalling," Journal of Cell Science, vol. 111, part 12, pp. 17411749, 1998.

[30] T. Husøy, H. K. Knutsen, V. Cruciani et al., "Connexin43 is overexpressed in $\mathrm{Apc}^{\mathrm{Min} /+}$-mice adenomas and colocalises with COX-2 in myofibroblasts," International Journal of Cancer, vol. 116, no. 3, pp. 351-358, 2005.

[31] Y. Araki, S. Okamura, S. P. Hussain et al., "Regulation of cyclooxygenase-2 expression by the Wnt and ras pathways," Cancer Research, vol. 63, no. 3, pp. 728-734, 2003. 
[32] M. Shtutman, J. Zhurinsky, I. Simcha et al., "The cyclin D1 gene is a target of the b-catenin/LEF-1 pathway," Proceedings of the National Academy of Sciences of the United States of America, vol. 96, no. 10, pp. 5522-5527, 1999.

[33] T. C. He, T. A. Chan, B. Vogelstein, and K. W. Kinzler, "PPARdelta is an APC-regulated target of nonsteroidal antiinflammatory drugs," Cell, vol. 99, no. 3, pp. 335-345, 1999.

[34] G. L. Nicolson, K. M. Dulski, and J. E. Trosko, "Loss of intercellular junctional communication correlates with metastatic potential in mammary adenocarcinoma cells," Proceedings of the National Academy of Sciences of the United States of America, vol. 85, no. 2, pp. 473-476, 1988.

[35] G. D. Carystinos, A. Bier, and G. Batist, "The role of connexinmediated cell-cell communication in breast cancer metastasis," Journal of Mammary Gland Biology and Neoplasia, vol. 6, no. 4, pp. 431-440, 2001.

[36] S. C. Chen, D. B. Pelletier, P. Ao, and A. L. Boynton, "Connexin43 reverses the phenotype of transformed cells and alters their expression of cyclin/cyclin-dependent kinases," Cell Growth and Differentiation, vol. 6, no. 6, pp. 681-690, 1995.

[37] F. Lecanda, D. A. Towler, K. Ziambaras et al., "Gap junctional communication modulates gene expression in osteoblastic cells," Molecular Biology of the Cell, vol. 9, no. 8, pp. 2249-2258, 1998.

[38] J. H. C. Lin, T. Takano, M. L. Cotrina et al., "Connexin43 enhances the adhesivity and mediates the invasion of malignant glioma cells," Journal of Neuroscience, vol. 22, no. 11, pp. 4302-4311, 2002.

[39] M. Mareel and A. Leroy, "Clinical, cellular, and molecular aspects of cancer invasion," Physiological Reviews, vol. 83, no. 2, pp. 337-376, 2003.

[40] Z. Ai, A. Fischer, D. C. Spray, A. M. C. Brown, and G. I. Fishman, "Wnt-1 regulation of connexin43 in cardiac myocytes," Journal of Clinical Investigation, vol. 105, no. 2, pp. 161-171, 2000.

[41] G. G. Chung, E. Provost, E. P. Kielhorn, L. A. Charette, B. L. Smith, and D. L. Rimm, "Tissue microarray analysis of beta-catenin in colorectal cancer shows nuclear phospho-betacatenin is associated with a better prognosis," Clinical Cancer Research, vol. 7, no. 12, pp. 4013-4020, 2001.

[42] A. Lugli, I. Zlobec, P. Minoo et al., "Prognostic significance of the wnt signalling pathway molecules APC, beta-catenin and E-cadherin in colorectal cancer: a tissue microarray-based analysis," Histopathology, vol. 50, no. 4, pp. 453-464, 2007.

[43] B. C. McKaig, S. S. Makh, C. J. Hawkey, D. K. Podolsky, and Y. R. Mahida, "Normal human colonic subepithelial myofibroblasts enhance epithelial migration (restitution) via TGF-beta3," American Journal of Physiology, vol. 276, no. 5, pp. G1087-G1093, 1999. 


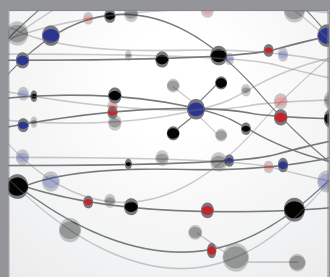

The Scientific World Journal
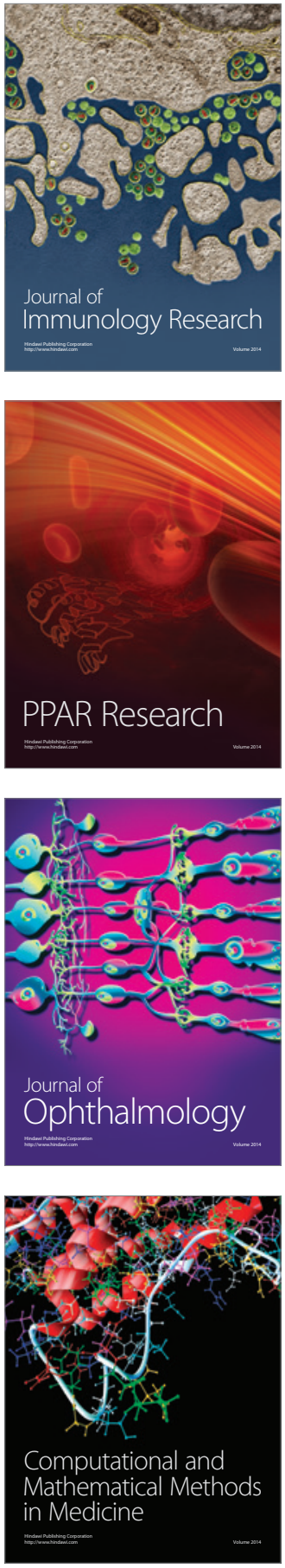

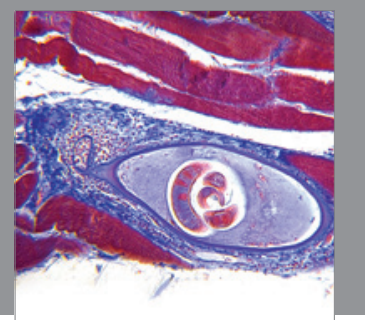

Gastroenterology

Research and Practice
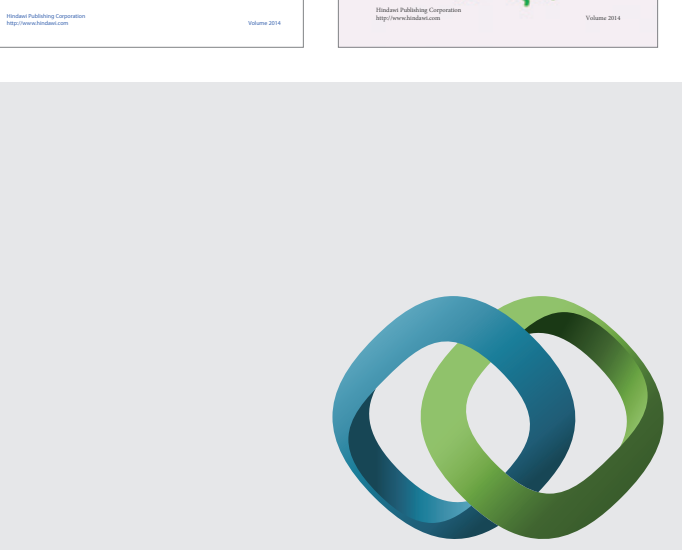

\section{Hindawi}

Submit your manuscripts at

http://www.hindawi.com
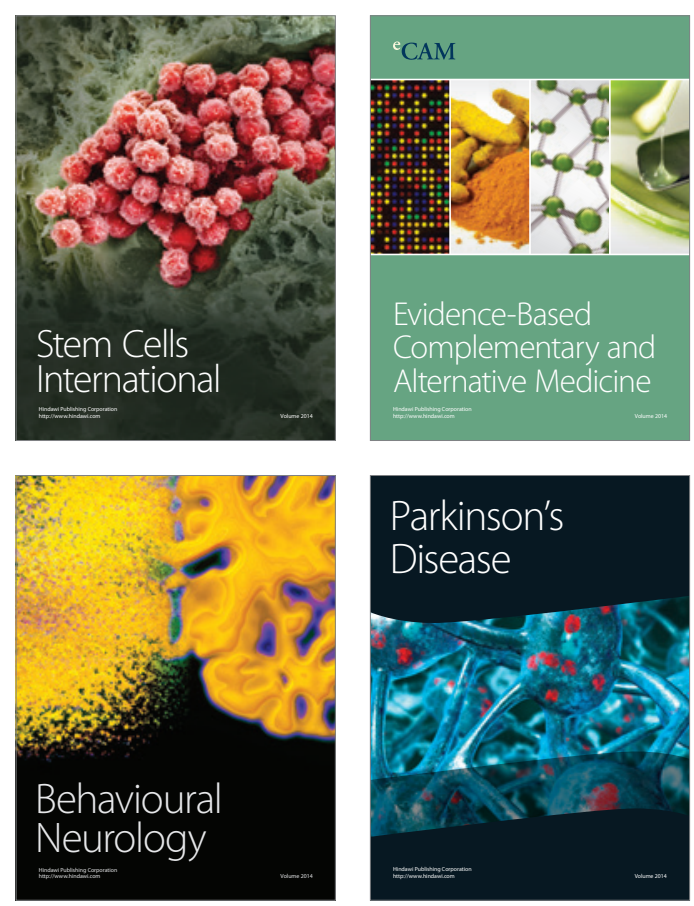

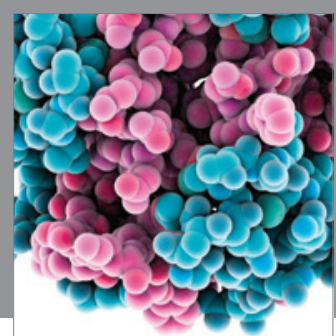

Journal of
Diabetes Research

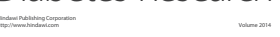

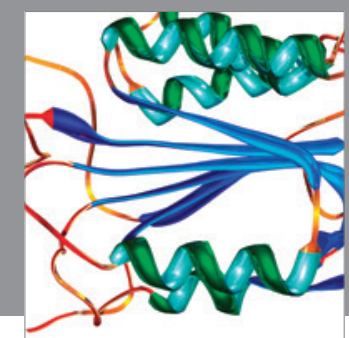

Disease Markers
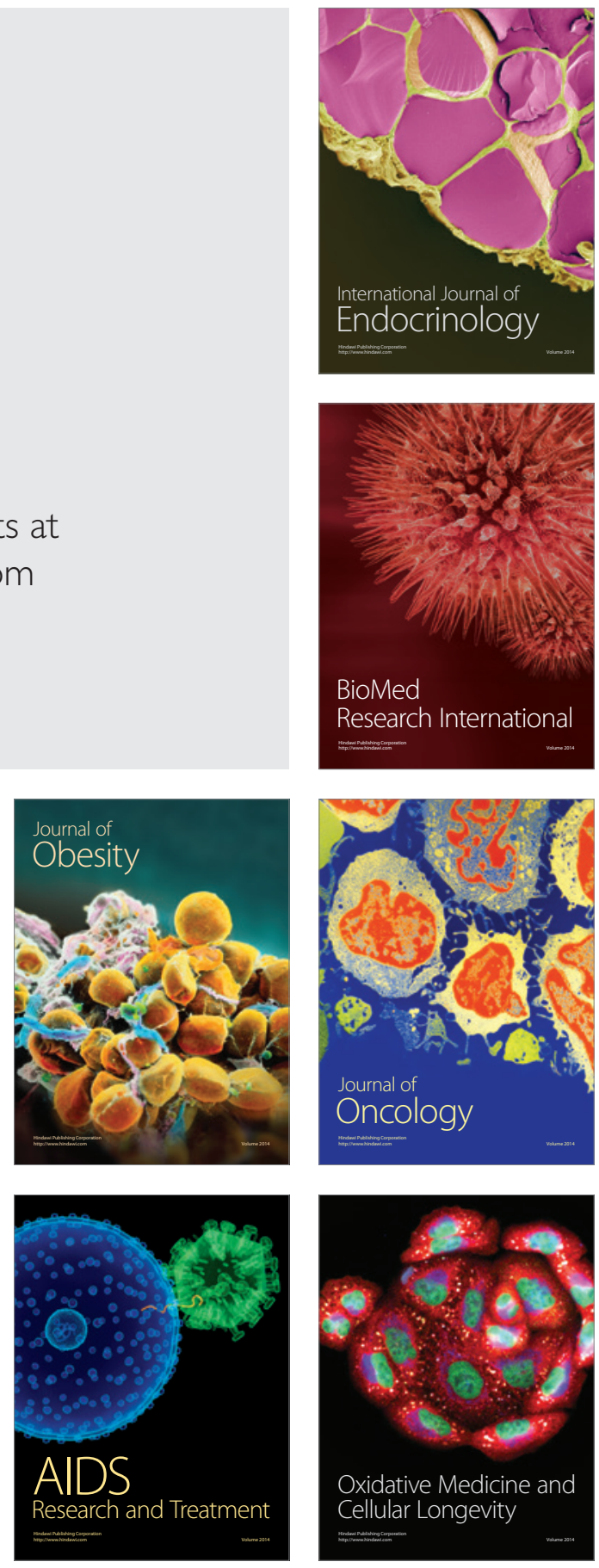